\title{
Aquifer evaluation in parts of north-central Nigeria from geo-electrical derived parameters
}

\author{
J. O. Naiyeju ${ }^{1} \cdot$ M. A. Oladunjoye ${ }^{2} \cdot$ M. A. Adeniran ${ }^{2}$ (I)
}

Received: 19 November 2020 / Accepted: 18 October 2021 / Published online: 26 October 2021

(c) The Author(s) 2021

\begin{abstract}
In order to reduce the level of risk associated with borehole drilling, it is important to have detailed knowledge about the aquifer distribution. In a view to generating groundwater potential model of Lokoja and its environs, the detailed subsurface characterization was carried out using a GIS-based multi-criteria decision analysis approach. One hundred and twenty-four vertical electrical sounding (VES) data points were covered within the study area using the Schlumberger array of electrical resistivity surveys. Hydrogeological investigation of one hundred and twenty-four existing boreholes within the vicinity of the sounded VES points was carried out by measuring in situ parameters of each borehole such as borehole depth, elevation, static water level and borehole yield. A Multi-Criteria Decision Analysis-Analytical Hierarchy Process (MCDA)-AHP-based was carried out by estimating the probabilistic ratings for the classes of parameters used for modeling groundwater potential. Four groundwater potential influencing factors, namely coefficient of anisotropy, transverse resistance, aquifer resistivity and aquifer thickness, were classified and rated. The output of the multi-criteria decision analysis was processed in the GIS environment to produce a groundwater potential index map. The obtained model was validated by comparing it with in situ borehole yield data to determine the accuracy of the proposed model. The groundwater potential map generated classified the study area into low, medium and high yield zones. Areas with medium potential zones dominate the largest part of the with $66 \%$ area coverage, and the dominance of these zones was visible in the northern and western part of the study area. Areas with high groundwater potential exist toward the southern and eastern sections of the study area. This area was observed to be underlined with sandstone, siltstone and migmatite. The validation exercise carried out on the proposed model reveals a $70 \%$ prediction accuracy.
\end{abstract}

Keywords Multi-criteria decision analysis · Groundwater potential index · Analytical hierarchy process · GIS

\section{Introduction}

The need for successful groundwater exploration planning and management for local and regional groundwater productivity mapping in the field of groundwater hydrology cannot be underestimated The importance of groundwater as a supply for a country's socioeconomic growth is enormous, as it remains the most solved water sources in many areas due to underdevelopment of surface water. Recent population growth has imposed significant stress on the existing

M. A. Adeniran

adeniranmargaret93@gmail.com

1 Mines Department, NIOMCO LTD, Itakpe, Kogi State, Nigeria

2 Department of Geology, University of Ibadan, Ibadan, Nigeria inadequate water scheme based solely on individual exploration exercises due to the increasing demand for water supply. Consequently, it became very expedient to expand the existing water scheme by carrying out detailed subsurface characterization, thereby leading to mapping out zones of high groundwater potentials.

Groundwater occurrence in any rock presupposes the satisfaction of two factors: adequate porosity and permeability. Sedimentary rocks exhibit these properties due to their mode of occurrence and emplacement. Sedimentary deposits maintain primary porosity that determines their storage and permeability to a great extent (Ashraf et al. 2018) which tends to make them exhibit good aquifer potential as compared to basement complex aquifers. The crystalline nature of the basement complex's metamorphic and igneous rocks satisfies none of these requirements. Basement complex rocks are therefore considered poor aquifers due to their 
low primary porosity and permeability, necessary for the accumulation of groundwater (Davies and De West 1966). Olorunfemi and Fasuyi (1993) emphasized the complexity of groundwater occurrence in a basement complex terrain which can be attributed to the occurrence of primary porosity in the underlying rock. The occurrence of groundwater in a basement complex terrain can be attributed to the degree of weathering and fracturing as well as the materials that make up the saprolite zone. The complex interrelationship between geology, post-emplacement, tectonic history, weathering process, aquifer types and groundwater flow pattern therefore plays an important role in groundwater potential in a basement complex (Olorunfemi 2007). The occurrence and distribution of groundwater in crystalline units are influenced by a variety of factors including the existence and development of integrated fracture system, fracturing intensity, nature and type of fillings in the joint aperture, depth, extent, weathering pattern and thickness. Taking into account the limited and winding characteristics of groundwater reservoirs in the basement complex, the optimum potential of the aquifer network can only be extracted through a well-coordinated hydro-geophysical and geological investigation. Geo-electrical techniques are powerful tools and play a vital role in groundwater investigations particularly in delineating the aquifer structure in complex geological environments. By combining data on hydrogeological surface characteristics with information obtained from geo-electrical investigations, the subsurface characteristics and details of aquifer morphology can thus be described. The hydrogeological significance of each geo-electric parameter used to model groundwater potential will then be a function of its contribution to the occurrence of groundwater. In other words, theoretical modeling of groundwater is a spatial analysis problem involving a broad range of multiple evaluation criteria.

Several experts frequently evaluate those criteria. Rao and Briz-Kishore (1991), Adiat et al. (2013) and Mogaji and Omobude (2017) assessed the value of aquifer resistivity and thickness for future groundwater evaluation. In order to produce a high-precision groundwater distribution map, the effects of all the important geo-electrical parameters have to be integrated (Adiat et al. 2013). The use of the multi-criteria decision analysis (MCDA) in the field of hydrogeology is comparatively new (Mogaji and Omobude 2017). The advantage of the approach is its ability to carry out a systemic analysis and to combine specific criteria/factors to model the target. The most commonly used MCDA method is the analytical hierarchic process (AHP) approach (Adiat et al. 2013; Jha et al. 2010; Mogaji and Lim 2016;
Mogaji and Omobude 2017). Many factors such as lithology, drainage pattern, lineament density and geo-electric parameters (thickness, resistivity, transverse resistance, coefficient of anisotropy) are believed to be influencing groundwater potential (Adiat et al. 2013; Mogaji and Lim 2016; Akinlalu et al. 2017). The invention of geographic information system (GIS) has made possible spatial distribution mapping and integration of different data sets. Its applicability in the field of hydrogeology has been widely explored (Nampak et al. 2014; Singh et al. 2014; Mogaji and Lim 2016; Mogaji and Omobude 2017). Their work has shown the effectiveness of GIS to carry out MCDA prediction models in environmental decision-making processes.

Though groundwater has in previous years been explored in the study area through the drilling of boreholes, however, some of these boreholes are characterized by low and intermediate yield. In order to reduce the level of risk associated with borehole drilling, it is important to have background knowledge about the groundwater potential distribution within the area and this can be done by carrying out a detailed study of the aquifer system and spatial distribution mapping of groundwater potential markers within the region. This study thus tends to develop MCDA-based groundwater potential model by integrating geophysical and GIS techniques.

\section{Location and geology of the study area}

The area investigated which encompasses Lokoja, and its environs is located between Latitudes $7^{\circ} 45^{\prime} 00^{\prime \prime}$ and $7^{\circ} 51^{\prime} 00^{\prime \prime}$ and Longitudes $6^{\circ} 38^{\prime} 30^{\prime \prime}$ to $6^{\circ} 44^{\prime} 00^{\prime \prime}$ at the north-central part of Nigeria with a total surface area of $123 \mathrm{~km}^{2}$ (Fig. 1). The geological setting of the study area consists of the occurrence of both basement complex and sedimentary rocks (Fig. 2). The western flank is covered by crystalline basement complex of Precambrian age, consisting of migmatite and migmatite gneiss, undifferentiated granite and granite gneiss and biotite hornblende gneiss. The eastern flank is covered by Cretaceous to Recent sediments of the southern Bida Basin such as alluvium and feldspathic sandstone and siltstone. The area falls within the Guinea Savannah climate belt of West Africa which is characterized by two distinct seasons, the wet and dry seasons. The average rainfall of Lokoja was found to be $1213.877 \mathrm{~mm}$ (Olatunde and Isaac 2018). The average annual temperature rarely falls below $30.7^{\circ} \mathrm{C}$, with February and March being the hottest months (Olatunde and Ukoje 2016). 


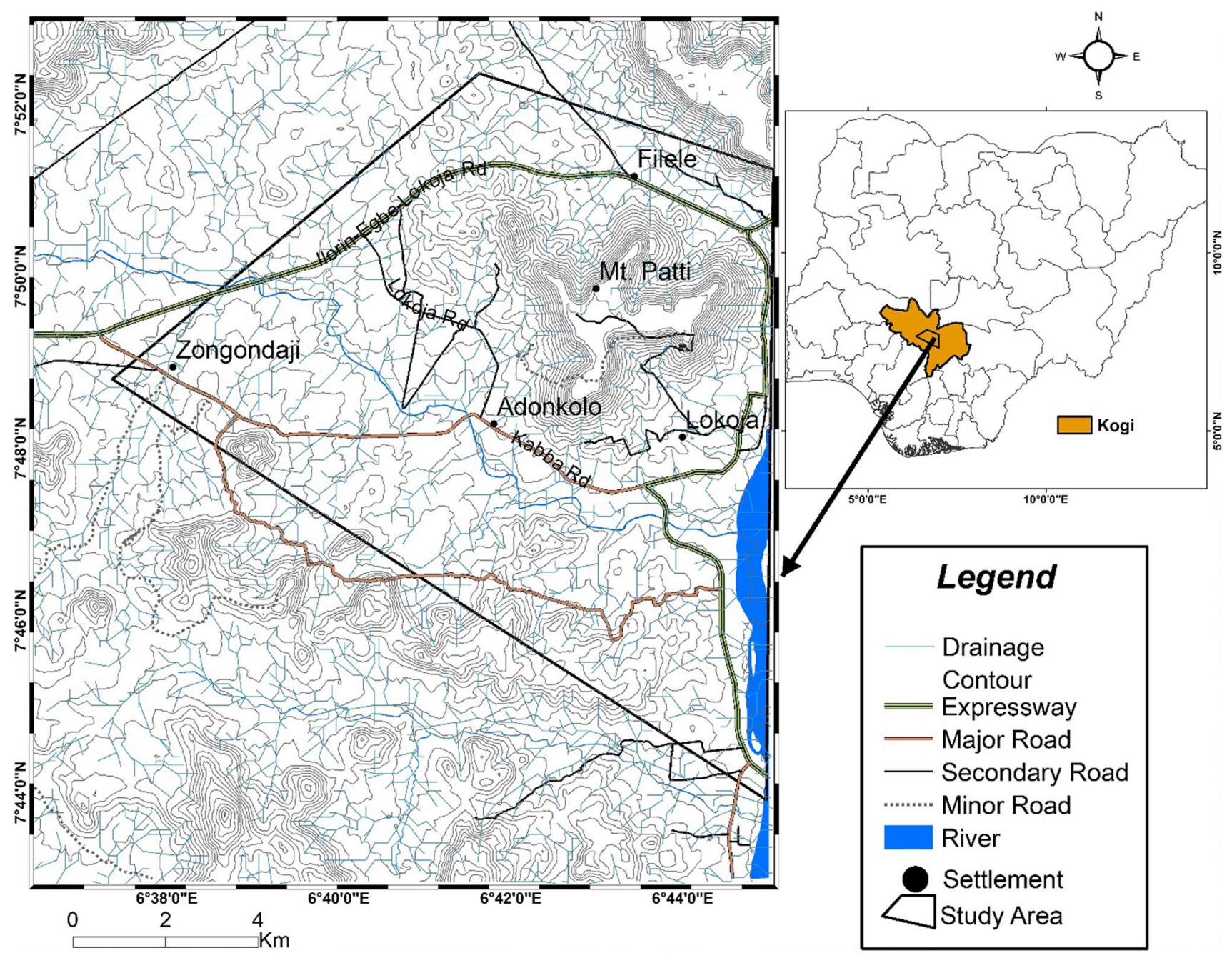

Fig. 1 Topographical map of the study area

\section{Methodology}

In order to carry out detailed subsurface characterization, both geophysical and hydrogeological investigation was employed. A total of one hundred and twenty-four (124) vertical electrical sounding (VES) (Fig. 3) data with a distribution density of $1.01 \mathrm{VES}$ per unit $\mathrm{km}^{2}$ were collected within the study area using the Schlumberger configuration of electrical resistivity survey with maximum $A B / 2$ spacing of $100 \mathrm{~m}$. The obtained data were plotted on a log-log graph. Master curves (Orellana and Mooney 1966) and auxiliary point charts (Zohdy 1965; Keller and Frischknecht, 1966) were used to manually classify the field curves. The layered parameter obtained from the manual interpretation was then used as an input model for the computer-aided iteration of the WINRESIST interpreting system (Vander Velpen 1988).
The sounding curves were interpreted to determine the true resistivity and thickness of the subsurface which was further interpreted to obtain the Dar-Zarrouk parameters. Hydrogeological investigation of one hundred and twenty-four (124) randomly selected boreholes drilled within the study area was undertaken to obtain in situ information on the subsurface (Fig. 3). Parameters such as elevation, static water level, borehole depth and borehole yield were obtained to determine the groundwater flow direction within the study area.

A Multi-Criteria Evaluation Analytic Hierarchy Process (MCE-AHP) approach developed by Saaty (1980) was employed to model groundwater potential. The influencing factor used for the prediction (aquifer thickness, aquifer resistivity, coefficient of anisotropy and transverse resistance) was classified and rated as shown in Table 1. A knowledge-based AHP classification was employed. Studies by Adiat et al. 


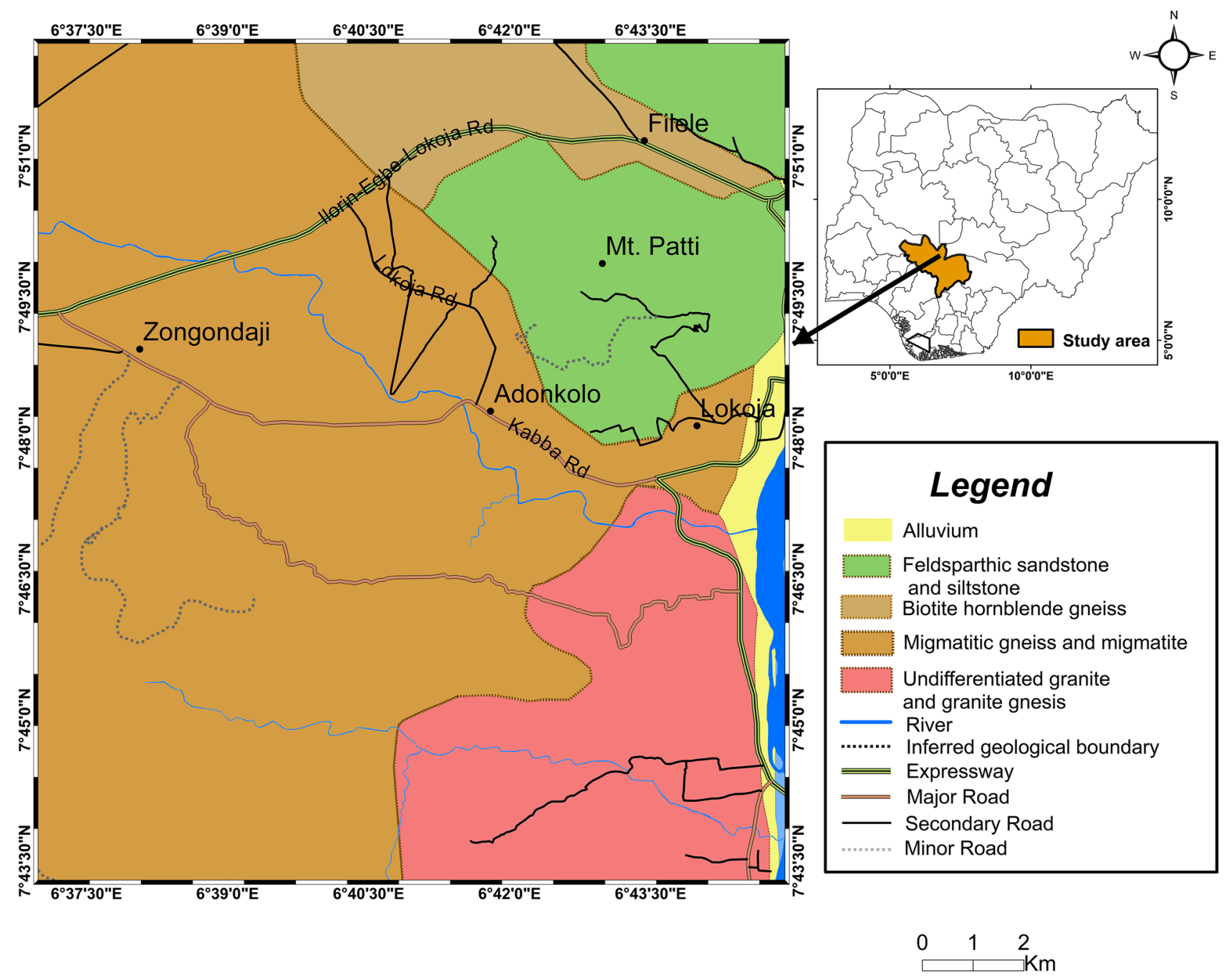

Fig. 2 Geological map of the study area (Ojoina 2014)

(2012), Adiat et al. (2013) and Mogaji and Lim (2016) have identified the hydrogeological importance of these influencing factors. Thematic maps for each predictor were generated having being assigned rates and weight on the numerical scale depending on the influence rate of each parameter on groundwater occurrence. A ranking scale of 1 to 3 was used with 1 being the lowest, 2 being the average and 3 being the highest. Groundwater potential index (GWPI) was estimated by applying the weighted linear combination as expressed in Eqs. 1 and 2.

Mathematically, according to Adiat et al. (2012), groundwater yield index for each VES point can be defined as:

$\mathrm{GW} Y I=W_{i} R_{i}$ where $W_{i}$ is the weight (w) of parameter $I$ and $R_{i}$ is the rating score (R) of parameter $i$.

Therefore, $\mathrm{GW}=f(\mathrm{CA}, \mathrm{AT}, \mathrm{BY}, \mathrm{AT})$ where $\mathrm{GW}$ is groundwater, CA is coefficient of anisotropy, AT is aquifer thickness, BY is borehole yield and AT is aquifer thickness.

According to Adiat et al. (2012), the groundwater potential index value is given by the equation:

$\mathrm{GWPI}=\mathrm{CA}_{w} \mathrm{CA}_{R}+\mathrm{AT}_{W} \mathrm{AT}_{R}+\mathrm{BY}_{W} \mathrm{BY}_{R}+\mathrm{AT}_{W} \mathrm{AT}_{R}$

The obtained groundwater potential index value obtained at each VES point was imported into an ArcGIS environment. Inverse distance weighting (IDW) geostatistical tool 


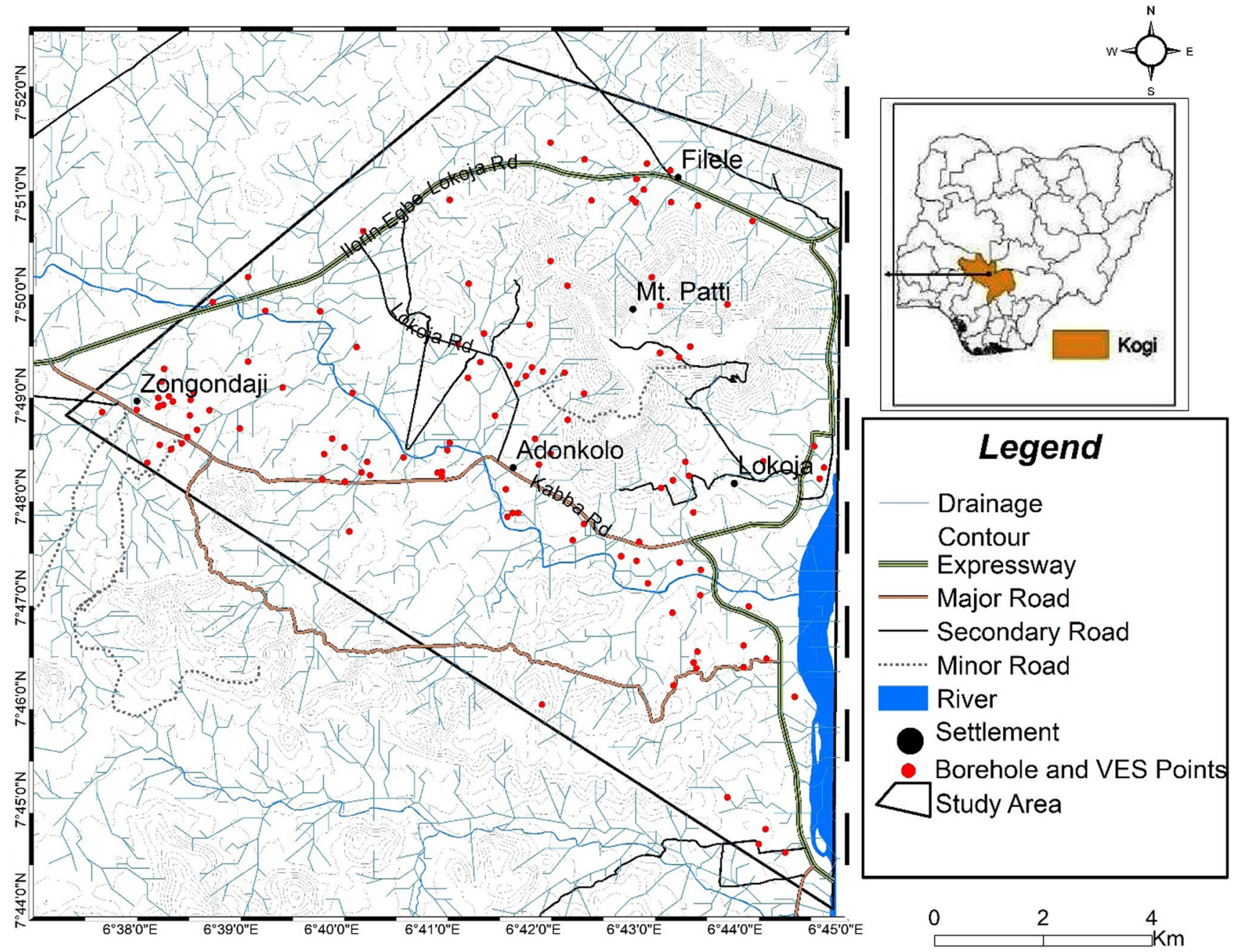

Fig. 3 Topological map showing the VES and borehole points

Table 1 Probability rating (R) for classes of the parameters (modified after Mogaji and Omobude 2017)

\begin{tabular}{|c|c|c|c|c|}
\hline Groundwater potential conditioning factor & Category (classes) & $\begin{array}{l}\text { Potential for groundwater } \\
\text { storage }\end{array}$ & Ratings (R) & $\begin{array}{l}\text { Normalized } \\
\text { weight (W) }\end{array}$ \\
\hline Transverse resistance (TR) & $\begin{array}{l}<1000 \\
1000-2500 \\
>2500\end{array}$ & $\begin{array}{l}\text { Low } \\
\text { Moderate } \\
\text { High }\end{array}$ & $\begin{array}{l}1 \\
2 \\
3\end{array}$ & 0.31 \\
\hline Coefficient of anisotropy (CA) & $\begin{array}{l}<1 \\
1-1.5 \\
1.51 .9\end{array}$ & $\begin{array}{l}\text { Low } \\
\text { Moderate } \\
\text { High }\end{array}$ & $\begin{array}{l}1 \\
2 \\
3\end{array}$ & 0.29 \\
\hline Aquifer resistivity (AR) & $\begin{array}{l}10-40 \\
40-100 \\
100-300\end{array}$ & $\begin{array}{l}\text { Low } \\
\text { Moderate } \\
\text { High }\end{array}$ & $\begin{array}{l}1 \\
2 \\
3\end{array}$ & 0.22 \\
\hline Aquifer thickness (AT) & $\begin{array}{l}2-10 \\
10-20 \\
>20\end{array}$ & $\begin{array}{l}\text { Low } \\
\text { Moderate } \\
\text { High }\end{array}$ & $\begin{array}{l}1 \\
2 \\
3\end{array}$ & 0.18 \\
\hline
\end{tabular}




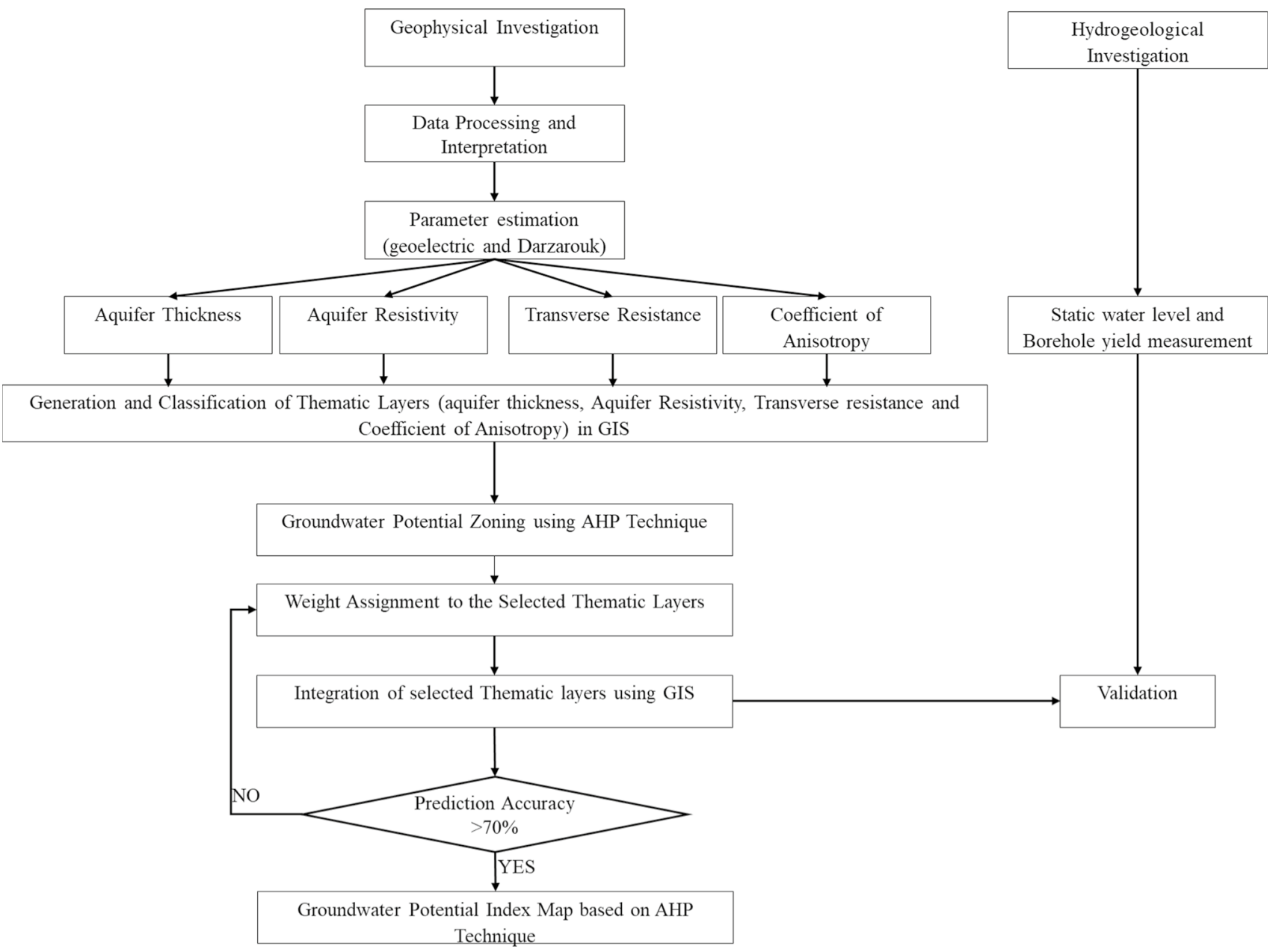

Fig. 4 Flowchart showing the methods used for the study

Table 2 Summary of aquifer parameters obtained from geo-electrical and hydrogeological interpretation

\begin{tabular}{llll}
\hline & Min & Max & Mean \\
\hline Elevation $(\mathrm{m})$ & 40 & 423 & 109 \\
Static water level $(\mathrm{m})$ & 4.00 & 16.00 & 6.59 \\
Water level $(\mathrm{m})$ & 32 & 417 & 102 \\
Transverse resistance $\left(\Omega \mathrm{m}^{2}\right)$ & 140 & 5891 & 1341 \\
Aquifer thickness $(\mathrm{m})$ & 2.10 & 56 & 12.44 \\
Aquifer resistivity $(\Omega \mathrm{m})$ & 11 & 250 & 111 \\
Coefficient of anisotropy & 0.6 & 1.8 & 1.21 \\
\hline
\end{tabular}

was employed to generate the groundwater potential map. Figure 4 shows a simplified flowchart of the methods used in this research.

\section{Results and discussion}

\section{Geophysical interpretation}

The layered parameter (resistivity and thickness) obtained from 1D electrical resistivity inversion was interpreted to obtain aquifer resistivity, aquifer thickness, coefficient of anisotropy. The longitudinal resistivity was interpreted to be the aquifer resistivity for areas underlined by basement rocks, while transverse resistivity was interpreted as aquifer resistivity for sedimentary terrain. These values were used as the aquifer resistivity in the study area since it is characterized by both longitudinal and transverse flow as described by Reiter (1981). 


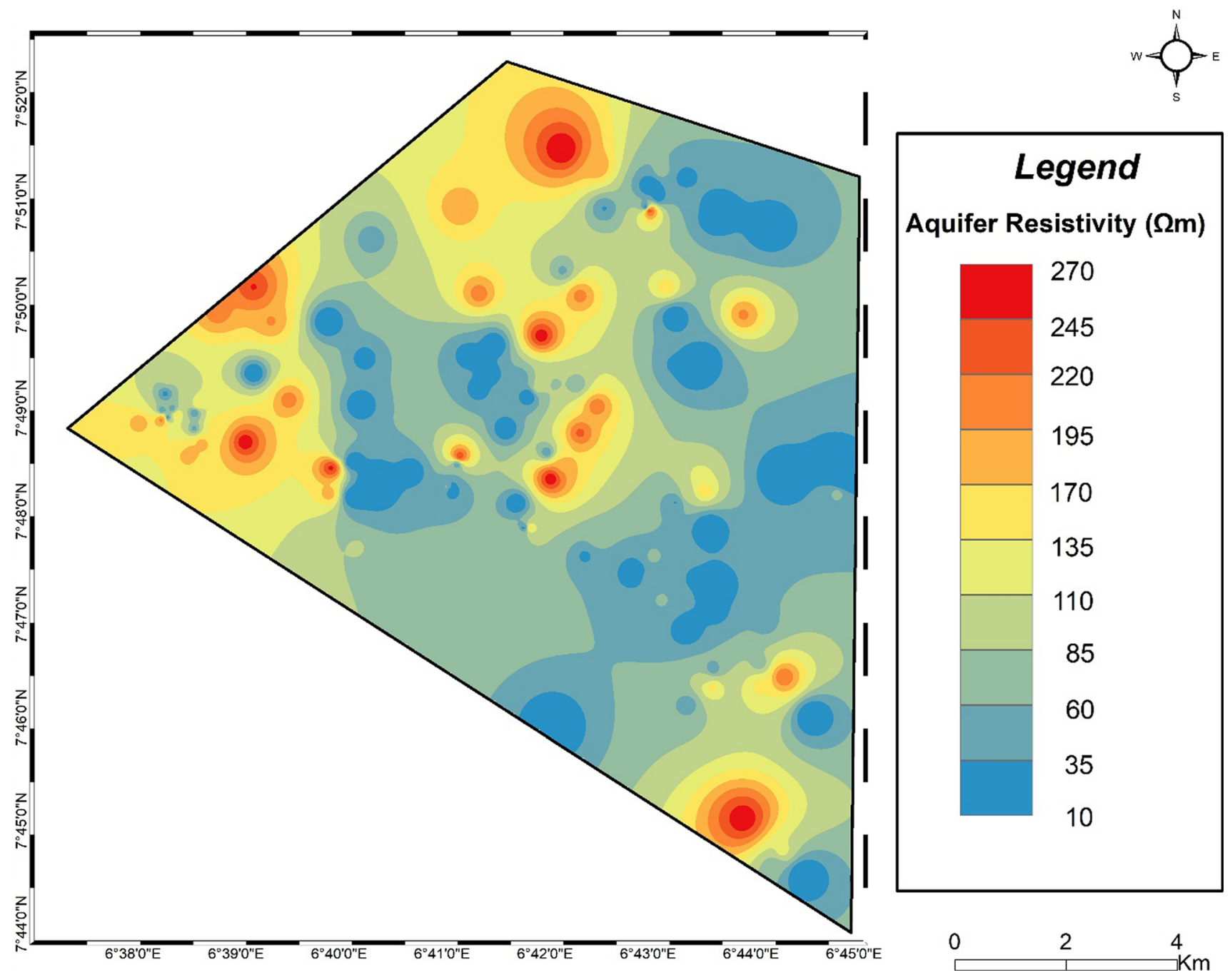

Fig. 5 Map showing the spatial distribution of aquifer resistivity across the study area

Aquifer resistivity value varies between 11 and $250 \Omega \mathrm{m}$ (mean: $111 \Omega \mathrm{m}$ ) (Table 2). Figure 5 illustrates the spatial distribution of aquifer resistivity of the study area. The central part is characterized with low resistivity ranging from 10 to $40 \Omega \mathrm{m}$. The low resistivity values can be inferred to represent good aquifer potential. The western and the southern part is characterized with medium $(40-100 \Omega \mathrm{m})$ to high (100-300 $\Omega \mathrm{m}$ ) resistivity values with pockets of low resistivity.

The aquifer thickness value varies between 2.1 and $55 \mathrm{~m}$ (mean: $12.44 \mathrm{~m}$ ). The spatial distribution map of aquifer thickness (Fig. 6) reveals its variation across the study area. $60 \%$ of the study area exhibits moderate aquifer thickness values $(10-20 \mathrm{~m})$ which is distributed across the northern and western parts of the study area. 35\% of the study area is characterized by low aquifer thickness values $(2-10 \mathrm{~m})$ and widely distributed in the southern part of the study area and as pockets within the moderate zones. $5 \%$ of the study area exhibit extremely high aquifer thickness values $(>20 \mathrm{~m})$, and they occur as pocket zones across the study area. High aquifer thickness creates a large space for the accommodation of infiltration water; however, the materials that make up these zones play a key impact in what quantity of the infiltration finally replenish the aquifer.

As the hardness and compaction of rocks increase, anisotropy also increases (Keller and Frischknecht 1966). Therefore, zones of high coefficient of anisotropy are always associated with low porosity and permeability. Areas with 


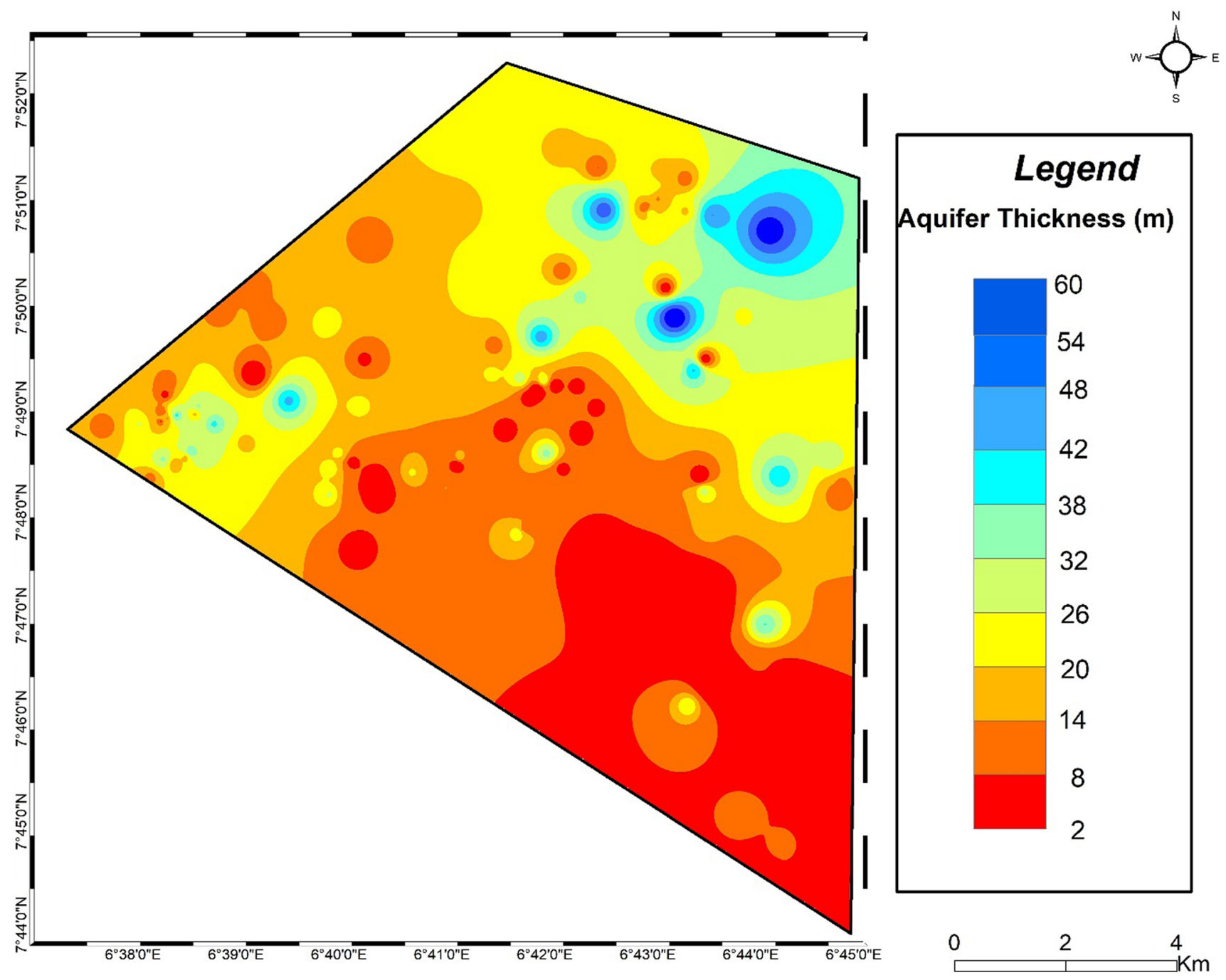

Fig. 6 Map showing the spatial distribution of aquifer thickness across the study area

a coefficient of anisotropy $<1$ are considered to have considerably high groundwater potential. As shown in Fig. 7, areas with sedimentary rocks have values less than 1 which confirms the availability of primary porosity in sedimentary rocks as compared to basement rocks.

Transverse resistance is a measure of the rate of water percolation and aquifer recharge, thus making it a suitable parameter in modeling groundwater potential. On an empirical basis, it can be admitted that the transmissivity of an aquifer is directly proportional to the transverse resistance (Ungemach et al. 1969). Figure 8 shows the spatial distribution of transverse resistance across the study area which is characterized by low $\left(<1000 \Omega \mathrm{m}^{2}\right)$ to medium $(1000-2500$ $\Omega \mathrm{m}^{2}$ transverse resistance values with isolated zones of high value. According to the groundwater flow map of the study area (Fig. 9) from the estimated hydraulic head shows that the most dominant groundwater flow is from the west through the central region to the eastern part of the study area. Localized flow direction from the northern to eastern region also exists.

\section{Modeling of groundwater potential based on MCA modeling approach}

The estimated groundwater potential index values were used to generate the spatial distribution of groundwater potential of the study area by adopting the quantile classification technique used in the studies of Mogaji and 


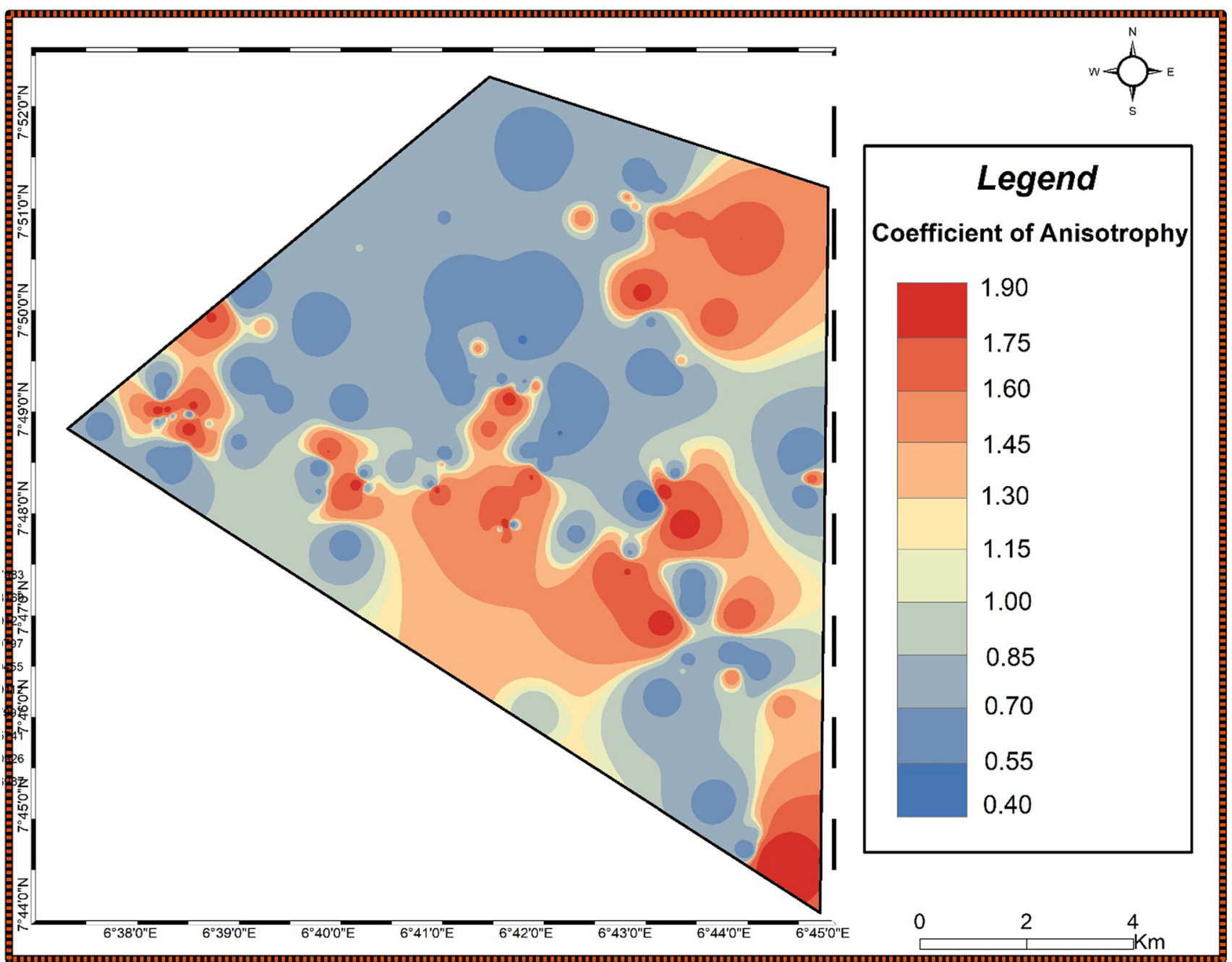

Fig. 7 Map showing the spatial distribution of coefficient of anisotropy across the study area

Omobude (2017) in which sets of values were distributed into classes of an equal number of values. The region groundwater potentiality prediction index (GPPI) maps were generated in a GIS setting using the classification ranges in column 2 of Table 3 . The generated groundwater potential yield index map (Fig. 10) classifies the potential rate into three classes (low, medium and high) using a spatial attribute band of $<1.4,1.4-2.6$, and $>2.6$ (Table 3 ). The corresponding percentage area covered in each groundwater potential zone is described in Table 3. From the result obtained, $66 \%$ of the study area can be described to exhibit medium rate groundwater potential with low and high zones having an area coverage of $22 \%$ and $10 \%$, respectively.

\section{Validation of the MCDA performance evaluation}

In order to evaluate the effectiveness of the groundwater potential model obtained, it is important to validate the result by comparing it with in situ aquifer measurement. According to Mogaji and Omobude (2017), validation is a method for ensuring the reliability of any proposed support system for decisions. The groundwater yield index map produced was validated using the borehole yield values obtained from a total of 124 boreholes. Using a qualitative comparison tool, the projected potential zone map (Fig. 10) was compared to the borehole yield map (Fig. 11). Table 4a, b summarizes the results of the validation. The GWYI map's prediction 


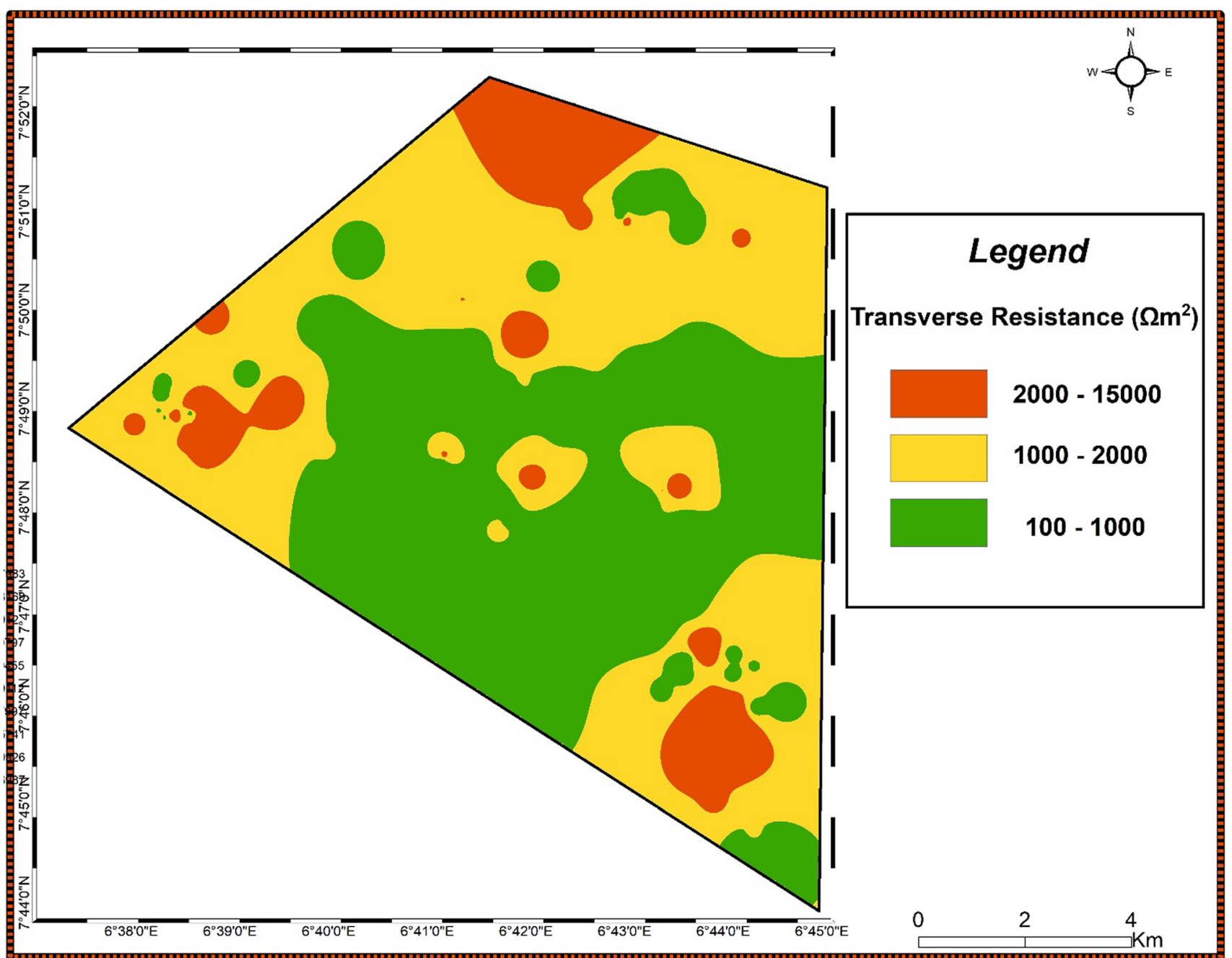

Fig. 8 Map showing the spatial distribution of transverse resistance across the study area

accuracy was evaluated quantitatively and found to be $70 \%$ predictable. Superimposing the obtained groundwater potential map on the geological map of the study, zones of high and medium potentials correlate with areas underlain by sedimentary rocks. A high potential zone was also observed within the migmatite and migmatite gneiss terrain, and this can be related to the heterogeneity of migmatitic rocks. Granites and granite gneiss were observed to exhibit low groundwater potential, and this can be attributed to a low rate of fracturing in these rocks. In general, the result suggested that geology plays an important factor in the groundwater potential of the study area.

\section{Conclusions}

A combined geophysical, hydrogeological and MCDAAHP GIS modeling approach has been used to predict groundwater potential within Lokoja and its environs. One hundred and twenty-four (124) VES data and aquifer information from the existing borehole were obtained. In the context of AHP, a multi-criteria decision analysis (MCDA) methodology was used to characterize the estimated geo-electric parameters to define suitable areas for groundwater exploration. To evaluate the model's predictive ability, the decision support model map produced was 


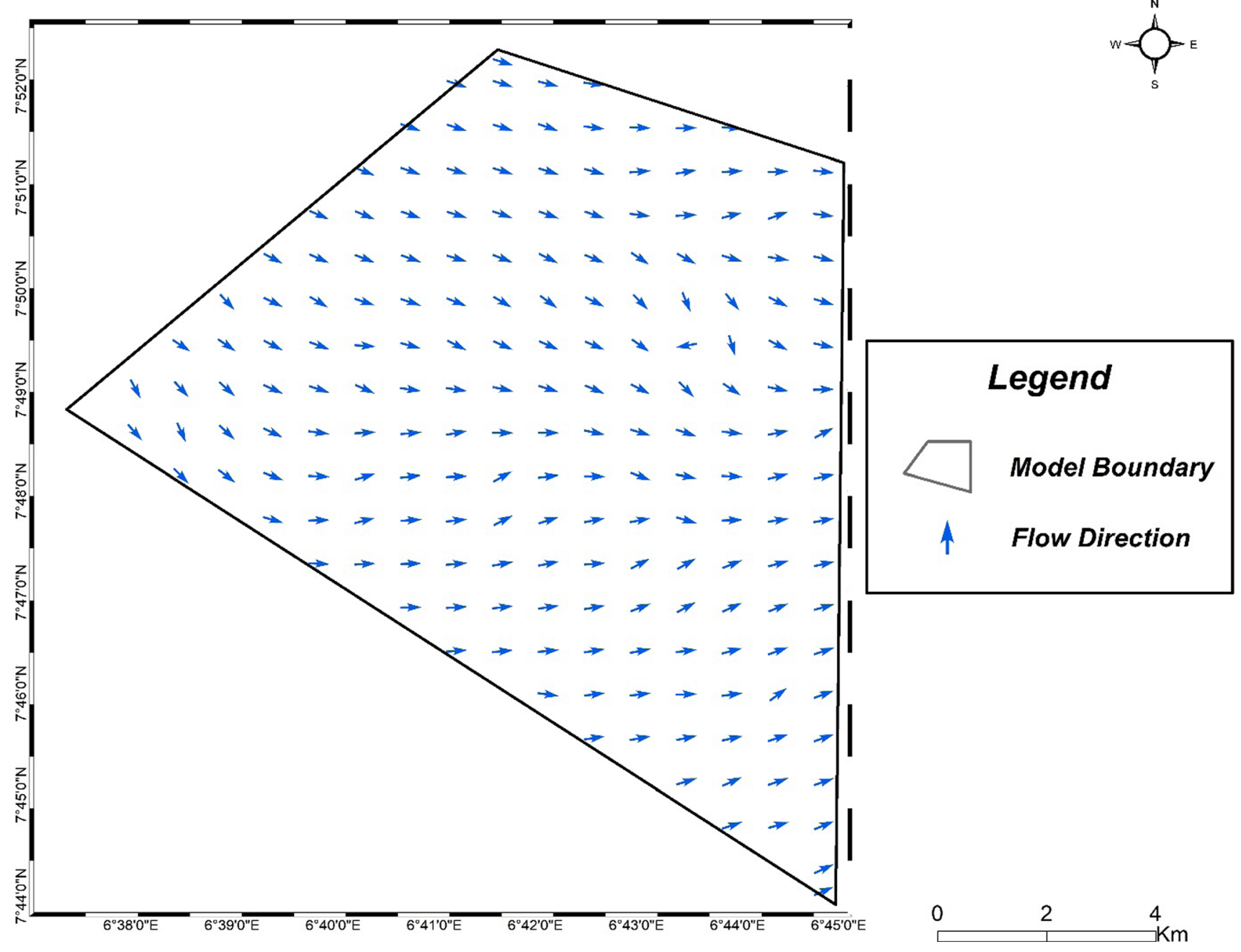

Fig. 9 Map showing the groundwater flow direction across the study area

compared with the in situ borehole yield values. The result obtained shows that the application of GIS and geophysical techniques has proven to be an effective and inexpensive method of characterizing and assessing the aquifer system. The darzarock parameters estimated from VES data reveal aquiver resistivity, aquifer thickness, transverse resistance and coefficient of anisotropy values varying from 11 to $250 \Omega \mathrm{m}, 2.1$ to $55 \mathrm{~m}, 140$ to $5891 \Omega \mathrm{m}^{2}$ and 0.6 to 1.8 , respectively, within the study area. The spatial

Table 3 Characteristics of the groundwater potential map based on the applied MCDA-AHP model (Mogaji and Omobude (2017)

\begin{tabular}{lll}
\hline $\begin{array}{l}\text { Potential index classifica- } \\
\text { tion }\end{array}$ & AHP model range & Area (\%) \\
\hline Low & $<1.4$ & 22 \\
Medium & $1.4-2.6$ & 66 \\
High & $>2.6$ & 10 \\
\hline
\end{tabular}

distribution maps reveal that the central part of the study area is characterized by low resistivity, thereby inferring a good aquifer potential. $60 \%, 35 \%$ and $5 \%$ of the study area exhibit moderate, low and high aquifer thickness values, respectively. The coefficient of anisotropy value obtained within the sedimentary terrains confirms the availability of primary porosity in sedimentary rock as compared to basement rocks. The dominant groundwater flow direction was revealed to be toward the eastern direction. The groundwater potential map generated was able to classify 


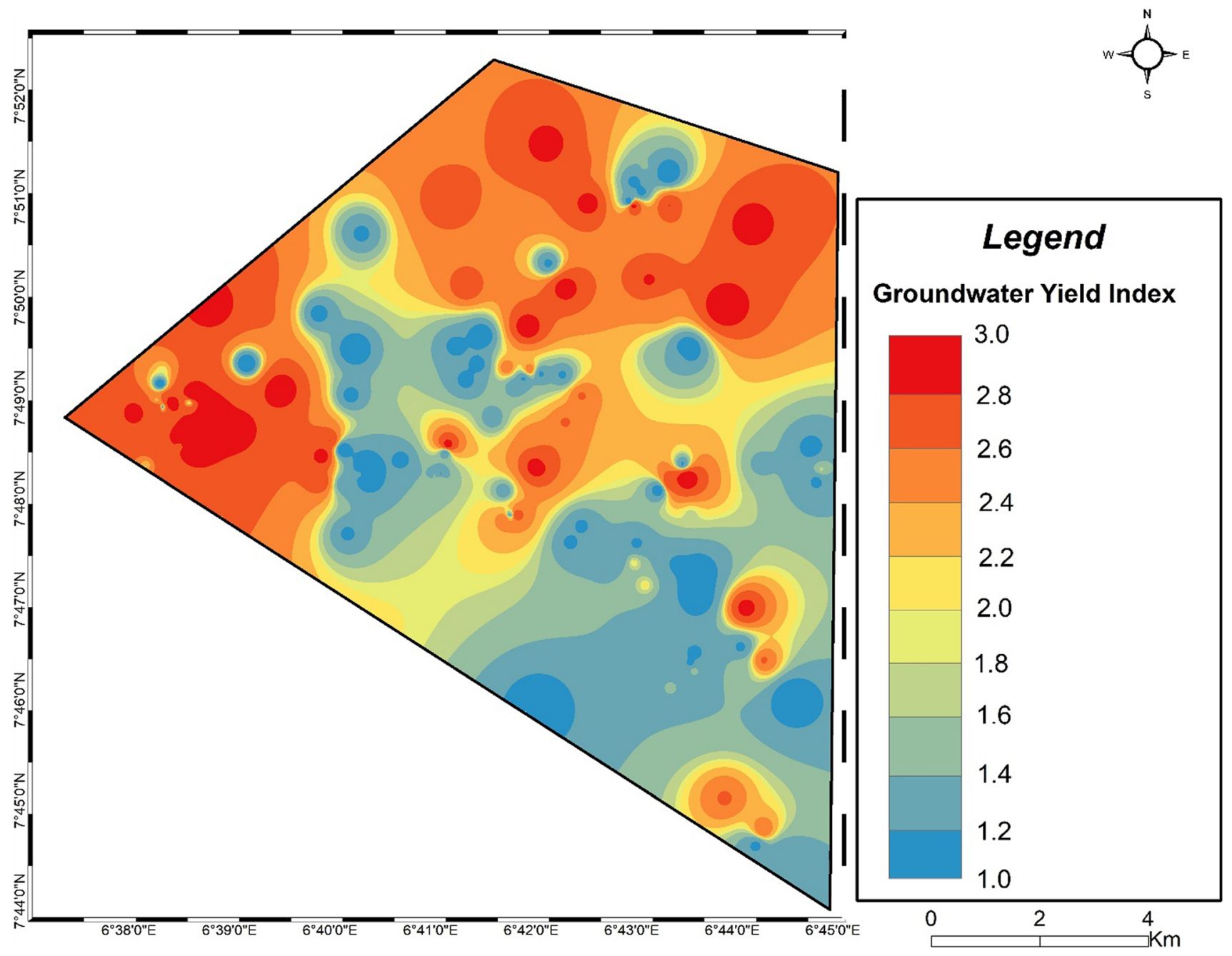

Fig. 10 Spatial distribution of groundwater yield index across the study area

the study area into low, medium and high yield zones. Areas with medium potential zones dominate the largest part of the study area having $66 \%$ area coverage with low and high zones having $22 \%$ and $10 \%$, respectively. Comparing the potential map to the geology map of the study region, it was discovered that sedimentary rock underpins the high and medium potential zones. Within the migmatite and migmatite gneiss terrain, a high potential zone was also discovered. Undifferentiated granite and granite gneiss were found to highlight the low potential region. The study shows that geology plays a significant role in the possible occurrence of groundwater in the subsurface. The validation carried out on the proposed model reveals a $70 \%$ prediction accuracy. 


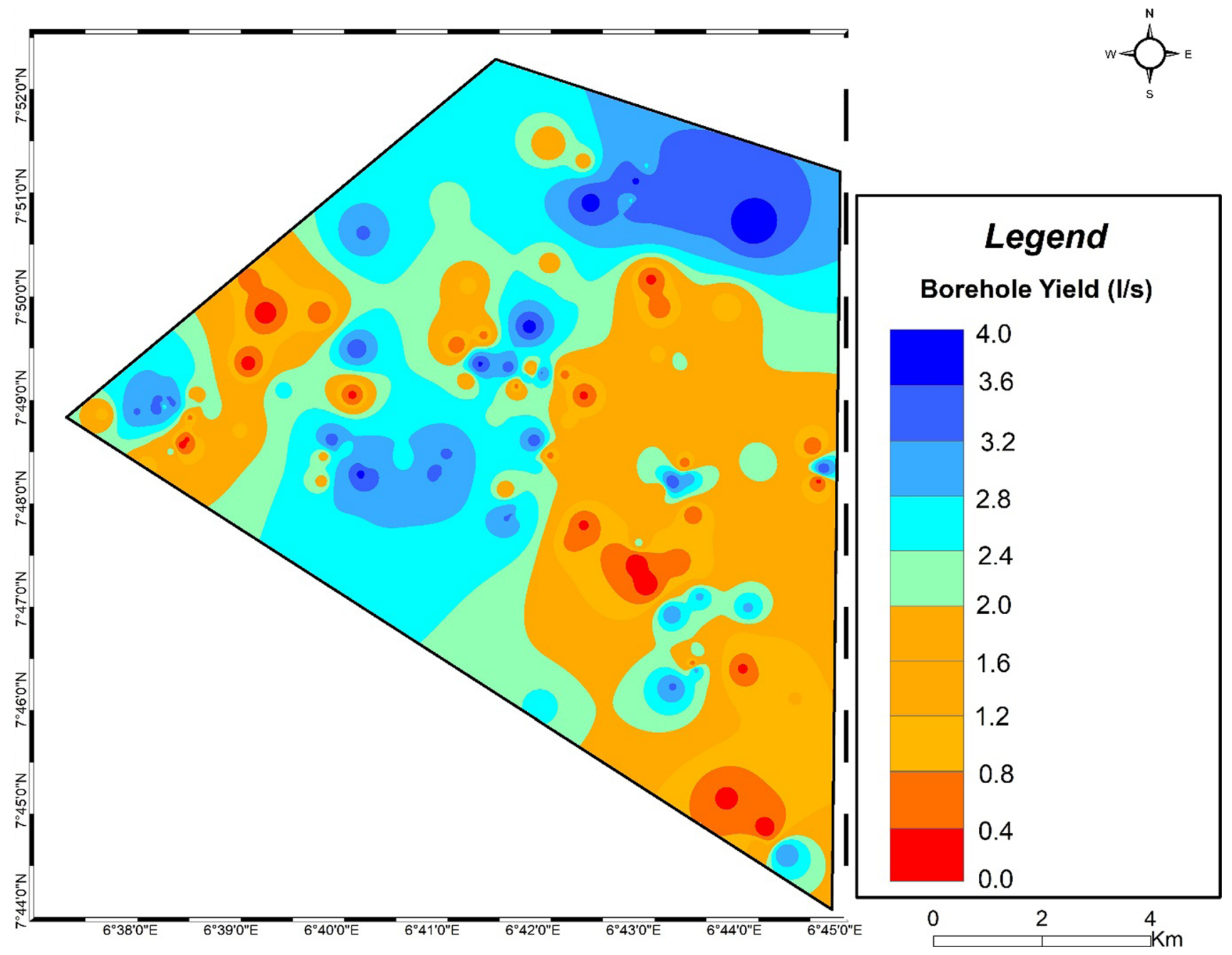

Fig. 11 Borehole yield across the study area 
Table 4 The spatial attribute comparative scheme qualitative result

\begin{tabular}{|c|c|c|c|c|c|c|c|c|c|}
\hline Borehole & Lat & Long & $\begin{array}{l}\text { Borehole } \\
\text { yield }(\mathrm{L} / \mathrm{s})\end{array}$ & $\begin{array}{l}\text { Attributes com- } \\
\text { parison remark }\end{array}$ & Borehole & Lat & Long & $\begin{array}{l}\text { Borehole } \\
\text { yield }(\mathrm{L} / \mathrm{s})\end{array}$ & $\begin{array}{l}\text { Attributes } \\
\text { comparison } \\
\text { remark }\end{array}$ \\
\hline \multicolumn{10}{|l|}{$a$} \\
\hline 1 & 7.7974 & 6.7264 & 1.1 & Agree & 39 & 7.8150 & 6.6382 & 2.6 & Agree \\
\hline 2 & 7.7891 & 6.7242 & 1 & Agree & 40 & 7.8486 & 6.7169 & 2.7 & Agree \\
\hline 3 & 7.7967 & 6.6957 & 2.4 & Agree & 41 & 7.8480 & 6.7272 & 2.8 & Agree \\
\hline 4 & 7.8206 & 6.7016 & 2.4 & Agree & 42 & 7.8039 & 6.6841 & 2.7 & Agree \\
\hline 5 & 7.8081 & 6.6688 & 1.9 & Disagree & 43 & 7.8439 & 6.6719 & 2.4 & Agree \\
\hline 6 & 7.8024 & 6.6688 & 2.3 & Agree & 44 & 7.7926 & 6.7175 & 1.8 & Agree \\
\hline 7 & 7.8284 & 6.6994 & 3.1 & Agree & 45 & 7.7732 & 6.7386 & 1.4 & Agree \\
\hline 8 & 7.7451 & 6.7384 & 0.7 & Disagree & 46 & 7.7669 & 6.7432 & 1.5 & Disagree \\
\hline 9 & 7.8180 & 6.6585 & 1.9 & Disagree & 47 & 7.8230 & 6.7241 & 1.8 & Agree \\
\hline 10 & 7.7894 & 6.7171 & 0.5 & Disagree & 48 & 7.8524 & 6.7170 & 2.9 & Disagree \\
\hline 11 & 7.8539 & 6.7226 & 2.7 & Disagree & 49 & 7.8064 & 6.6785 & 1.9 & Agree \\
\hline 12 & 7.8040 & 6.6716 & 3.1 & Disagree & 50 & 7.8486 & 6.7228 & 2.6 & Agree \\
\hline 13 & 7.8034 & 6.7257 & 2.2 & Disagree & 51 & 7.8216 & 6.6960 & 2.6 & Agree \\
\hline 14 & 7.8248 & 6.7259 & 1.6 & Disagree & 52 & 7.7973 & 6.6966 & 2.4 & Agree \\
\hline 15 & 7.8027 & 6.7231 & 2.8 & Agree & 53 & 7.8083 & 6.7464 & 1.1 & Agree \\
\hline 16 & 7.7744 & 6.7271 & 1.8 & Agree & 54 & 7.8048 & 6.7480 & 2.7 & Agree \\
\hline 17 & 7.8550 & 6.7188 & 2 & Agree & 55 & 7.7716 & 6.7269 & 2.2 & Agree \\
\hline 18 & 7.7688 & 6.7232 & 2.4 & Agree & 56 & 7.8143 & 6.6464 & 1.8 & Disagree \\
\hline 19 & 7.8157 & 6.6404 & 2.5 & Disagree & 57 & 7.8321 & 6.6470 & 1.7 & Disagree \\
\hline 20 & 7.8110 & 6.6444 & 1.6 & Disagree & 58 & 7.7726 & 6.7265 & 1.1 & Agree \\
\hline 21 & 7.8222 & 6.6913 & 2.9 & Disagree & 59 & 7.8507 & 6.7183 & 2.7 & Agree \\
\hline 22 & 7.8098 & 6.6428 & 0.9 & Disagree & 60 & 7.8199 & 6.6988 & 2 & Agree \\
\hline 23 & 7.8148 & 6.6379 & 2.6 & Agree & 61 & 7.8165 & 6.6397 & 2.4 & Agree \\
\hline 24 & 7.7818 & 6.7356 & 2.1 & Agree & 62 & 7.8095 & 6.7003 & 2.6 & Agree \\
\hline 25 & 7.8058 & 6.7380 & 1.8 & Agree & 63 & 7.8041 & 6.6849 & 2.3 & Agree \\
\hline 26 & 7.8253 & 6.6875 & 1 & Agree & 64 & 7.8014 & 6.7211 & 1.5 & Agree \\
\hline 27 & 7.8053 & 6.7009 & 1.9 & Agree & 65 & 7.8151 & 6.6388 & 1.7 & Agree \\
\hline 28 & 7.8247 & 6.6708 & 2.6 & Disagree & 66 & 7.8159 & 6.6433 & 1.8 & Agree \\
\hline 29 & 7.8076 & 6.6858 & 2.5 & Agree & 67 & 7.8171 & 6.6438 & 1.5 & Disagree \\
\hline 30 & 7.8205 & 6.7052 & 1.2 & Agree & 68 & 7.8133 & 6.6936 & 1.8 & Agree \\
\hline 31 & 7.8269 & 6.6918 & 1.2 & Disagree & 69 & 7.7837 & 6.7276 & 2.1 & Disagree \\
\hline 32 & 7.7718 & 6.7348 & 0.9 & Agree & 70 & 7.8095 & 6.6667 & 2.6 & Agree \\
\hline 33 & 7.8163 & 6.6380 & 2.5 & Agree & 71 & 7.8489 & 6.7096 & 3.1 & Disagree \\
\hline 34 & 7.7808 & 6.7230 & 2.3 & Agree & 72 & 7.8134 & 6.6432 & 1.2 & Agree \\
\hline 35 & 7.7857 & 6.7189 & 0.6 & Disagree & 73 & 7.7503 & 6.7321 & 0.9 & Disagree \\
\hline 36 & 7.7902 & 6.7145 & 1.1 & Agree & 74 & 7.7943 & 6.6696 & 1.9 & Agree \\
\hline 37 & 7.8088 & 6.6419 & 0.8 & Disagree & 75 & 7.7928 & 6.7065 & 1.2 & Agree \\
\hline 38 & 7.8143 & 6.6344 & 2.4 & Agree & 76 & 7.7412 & 6.7417 & 2.3 & Agree \\
\hline \multicolumn{10}{|l|}{$b$} \\
\hline 77 & 7.8455 & 6.7362 & 3.5 & Agree & 101 & 7.8029 & 6.7473 & 0.9 & Disagree \\
\hline 78 & 7.8033 & 6.6849 & 2.1 & Agree & 102 & 7.8170 & 6.7084 & 0.9 & Disagree \\
\hline 79 & 7.8013 & 6.6954 & 1.5 & Agree & 103 & 7.8127 & 6.7057 & 1.4 & Agree \\
\hline 80 & 7.8089 & 6.6862 & 2.1 & Agree & 104 & 7.8389 & 6.7028 & 1.6 & Agree \\
\hline 81 & 7.9544 & 6.7186 & 2.2 & Agree & 105 & 7.8584 & 6.7028 & 1.5 & Agree \\
\hline 82 & 7.8078 & 6.6401 & 1.8 & Agree & 106 & 7.8171 & 6.6701 & 0.9 & Disagree \\
\hline 83 & 7.8186 & 6.6973 & 1.2 & Agree & 107 & 7.8306 & 6.6648 & 1.1 & Agree \\
\hline 84 & 7.7754 & 6.7348 & 1.3 & Agree & 108 & 7.8223 & 6.6528 & 0.8 & Agree \\
\hline
\end{tabular}


Table 4 (continued)

\begin{tabular}{llllllllll}
\hline Borehole & Lat & Long & $\begin{array}{l}\text { Borehole } \\
\text { yield (L/s) }\end{array}$ & $\begin{array}{l}\text { Attributes com- } \\
\text { parison remark }\end{array}$ & Borehole & Lat & Long & $\begin{array}{l}\text { Borehole } \\
\text { yield (L/s) }\end{array}$ & $\begin{array}{l}\text { Attributes } \\
\text { comparison } \\
\text { remark }\end{array}$ \\
\hline 85 & 7.7955 & 6.7084 & 0.9 & Disagree & 109 & 7.8307 & 6.6557 & 0.7 & Disagree \\
86 & 7.7879 & 6.7277 & 1.4 & Disagree & 110 & 7.9224 & 6.6640 & 1.2 & Agree \\
87 & 7.7426 & 6.7373 & 1.6 & Agree & 111 & 7.8237 & 6.7209 & 1.4 & Agree \\
88 & 7.7656 & 6.7014 & 1.9 & Disagree & 112 & 7.8196 & 6.6892 & 1.5 & Agree \\
89 & 7.7973 & 6.6975 & 1.8 & Agree & 113 & 7.8490 & 6.6862 & 1.8 & Agree \\
90 & 7.8492 & 6.7163 & 1.9 & Disagree & 114 & 7.8362 & 6.7196 & 0.9 & Disagree \\
91 & 7.8057 & 6.6725 & 2.2 & Disagree & 115 & 7.8139 & 6.6287 & 1.4 & Agree \\
92 & 7.8035 & 6.6730 & 2.4 & Disagree & 116 & 7.8056 & 6.6362 & 1.3 & Agree \\
93 & 7.8211 & 6.6389 & 2.1 & Agree & 117 & 7.8070 & 6.6654 & 1.6 & Agree \\
94 & 7.8085 & 6.6382 & 1.6 & Agree & 118 & 7.8028 & 6.6651 & 1.6 & Agree \\
95 & 7.8211 & 6.6389 & 1.9 & Agree & 119 & 7.8071 & 6.7028 & 1.2 & Agree \\
96 & 7.8190 & 6.6385 & 2.1 & Disagree & 120 & 7.8057 & 6.7251 & 1.1 & Agree \\
97 & 7.8363 & 6.6528 & 1.2 & Agree & 121 & 7.8318 & 6.7321 & 1.3 & Disagree \\
98 & 7.8213 & 6.6998 & 1.3 & Agree & 122 & 7.8557 & 6.7084 & 1.6 & Agree \\
99 & 7.8351 & 6.6893 & 1.4 & Agree & 123 & 7.8348 & 6.7056 & 1.8 & Agree \\
100 & 7.8315 & 6.7210 & 1.1 & Agree & 124 & 7.8112 & 6.6514 & 1.4 & Agree \\
\hline
\end{tabular}

Funding The authors received no specific funding for this work.

Availability of data and material Available under request.

\section{Declarations}

Conflict of interest The authors declare that they have no known competing financial interests or personal relationships that could have appeared to influence the work reported in this paper.

Ethical standards This article does not contain any studies involving human participants performed by any of the authors.

Open Access This article is licensed under a Creative Commons Attribution 4.0 International License, which permits use, sharing, adaptation, distribution and reproduction in any medium or format, as long as you give appropriate credit to the original author(s) and the source, provide a link to the Creative Commons licence, and indicate if changes were made. The images or other third party material in this article are included in the article's Creative Commons licence, unless indicated otherwise in a credit line to the material. If material is not included in the article's Creative Commons licence and your intended use is not permitted by statutory regulation or exceeds the permitted use, you will need to obtain permission directly from the copyright holder. To view a copy of this licence, visit http://creativecommons.org/licenses/by/4.0/.

\section{References}

Adiat KAN, Nawawi MNM, Abdullah K (2012) Assessing the accuracy of GIS-based elementary multi criteria decision analysis as a spatial prediction tool- a case of predicting potential zones of sustainable groundwater resources. J Hydrol 440:75-89
Adiat KAN, Nawawi MNM, Abdullah K (2013) Application of multicriteria decision analysis to geoelectric and geologic parameters for spatial prediction of groundwater resources potential and aquifer evaluation. Pure Appl Geophys 170:453-471

Akinlalu AA, Adegbuyiro A, Adiat KAN, Akeredolu BE, Lateef WY (2017) Application of multi-criteria decision analysis in prediction of groundwater resources potential: a case of Oke-Ana, Ilesa Area Southwestern, Nigeria. NRIAG J Astron Geophys 6(1):184-200

Ashraf MAM, Yosoh R, Sazalil MA, Abidin MHZ (2018) Aquifer characterization and groundwater potential evaluation in sedimentary rock formation. J Phys Conf Ser 995:012106

Davies and De West (1966) Evolution de la croute continental au Nord Nigeria: apport de lageochimie, dela geochronologic U-Pbet des traceursisotopiques $\mathrm{Sr}, \mathrm{N}$, det $\mathrm{Pb}$.: (Doctorate Thesis, 194p). University of Science and Technology, Languedoc, Montpellier

Jha M, Chowdary V, Chowdhury A (2010) Groundwater assessment in Salboni Block, West Bengal (India) using remote sensing, geographical information system and multi-criteria decision analysis techniques. Hydrogeol J 18:1713-1728

Keller GV, Frischknecht FC (1966) Electrical methods in geophysical prospecting. Pergamon Press, pp 179-187

Mogaji KA, Lim HS (2016) Groundwater potentiality mapping using geoelectrical-based aquifer hydraulic parameters: a GIS-based multi-criteria decision analysis modeling approach. Terr Atmos Ocean Sci J. https://doi.org/10.3319/TAO.2016.11.01.02

Mogaji KA, Omobude OB (2017) Modeling of geoelectric parameters for assessing groundwater potentiality in a multifaceted geologic terrain, Ipinsa Southwest, Nigeria—a GIS-based GODT approach. NRIAG J Astron Geophys 6:434-451

Nampak H, Pradhan B, Manap MA (2014) Application of GIS based data driven evidential belief function model to predict groundwater potential zonation. J Hydrol 513:283-300

Ojoina OA (2014) Hydrogeophysical investigation of groundwater in Lokoja Metropolis, Kogi State, Central Nigeria. J Geogr Geol 6(1). ISSN 1914-9779

Olatunde AF, Isaac A (2018) Rainfall characteristics in Lokoja from 1981 to 2015. J Res Dev Arts Soc Sci 2:228-242

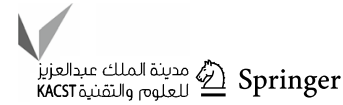


Olatunde AF, Ukoje JE (2016) Perception of causes, effects and use of local adaptive measures for mitigating thermal discomfort in Lokoja, Kogi State, Nigeria. J Contemp Urbanol 3(1):57-68

Olorunfemi MO (2007) Voyage on the skin of the earth: a geophysical experience. Inaugural Lecture Series 211, Obafemi Awolowo University, Ile-Ife, pp 1-2

Olorunfemi MO, Fasuyi SA (1993) Aquifer types and the geoelectric/ hydrogeologic characteristics of part of central basement terrain of Nigeria (Niger State). J Afr Earth Sci 16(3):309-317

Orellana E, Mooney HM (1966) Tables of master curves for vertical electrical sounding. Interciencia Madrid 160

Rao BV, Briz-Kishore BH (1991) A methodology for locating potential aquifers in a typical semi-arid region in India using resistivity and hydrogeologic parameters. Geoexploration 27:55-64

Reiter PF (1981) A computer study of the correlation between aquifer hydraulic and electrical properties. Thesis presented to the University of Rhode Island at Kingstone R. I, in partial fulfilment of the requirement for the degree of Master of Science

Saaty TL (1980) The analytic hierarchy process. McGraw-Hill, New York
Singh A, Srivastav SK, Kumar S, Chakrapani GJ (2014) A modifiedDRASTIC model (DRASTICA) for assessment of groundwater vulnerability to pollution in an urbanized environment in Lucknow, India. J Environ Earth Sci. https://doi.org/10.1007/ s12665-015-4558-5.

Ungemach P, Mostaghimi F, Duprat A (1969) Tests for determination of storage coefficient in unconfined aquifer and application in alluvial aquifer of Rhin. Bull Int Assoc Sci Hydrol 14:169-190

Vander Velpen BPA (1988) Resist version 1.0. M.Sc. Research Project, ITC: Delft, Netherlands

Zohdy AA (1965) The auxiliary point method of electrical resistivity imaging for investigation of a landslide along highway. Int J Phys Sci 6(24):5843-5849

Publisher's Note Springer Nature remains neutral with regard to jurisdictional claims in published maps and institutional affiliations. 